\title{
Proceeding
}

Supplementary Issue: Winter Conferences of Sports Science. Costa Blanca Sports Science Events, 22-23 March 2021. Alicante, Spain.

\section{Emotional characteristics of sportsman students engaged in bullying and cyberbullying in relation to migrant students}

\author{
RAMIL R. GARIFULLIN \\ Department of Pedagogical Psychology, Kazan (Volga Region) Federal University, Kazan, Russian \\ Federation
}

\begin{abstract}
The goal of this paper was to find a way to predict cyberbullying based on an assessment of the emotional insensitivity of university and college students. In addition, the goal was to study the intermediate mechanisms of regulating the relationship of emotional insensitivity and cyberbullying. The fundamental basis of this study was the assessment of emotional insensitivity using the method of "Determining the signs of emotional insensitivity". This assessment was made using a questionnaire that included three parts: callousness, indifference, and lack of emotion. This research has shown that empathy mitigates the adverse effects of emotional insensitivity on the processes of justification of immorality and according to the correlation analysis, there is a negative effect of the justification of immorality on cyberbullying. This study is an important step in revealing the emotional characteristics of students who are inclined to engage in cyberbullying. It is shown that the phenomenon of justification of cyberbullying is one of the potential mechanisms by which emotional features begin to affect the ability of students to engage in cyberbullying. Attention to the phenomenon of justification of cyberbullying reveals the relationship of emotional characteristics and cyberbullying. The conclusions of this study can be the basis for successful psychocorrection of students engaged in cyberbullying. The scientific novelty of this research is to reveal the mechanisms of interaction of emotional insensitivity, empathy and justification of immoral behaviour of students engaged in cyberbullying. Keywords: Sportsman student; Emotional insensitivity; Immorality; Moral degradation; Bullying; Cyberbullying; Empathy; Justification of immoral behaviour.

Cite this article as:

Garifullin, R.R. (2021). Emotional characteristics of sportsman students engaged in bullying and cyberbullying in relation to migrant students. Journal of Human Sport and Exercise, 16(3proc), S1207-S1215. https://doi.org/10.14198/jhse.2021.16.Proc3.37

Corresponding author. Department of Pedagogical Psychology, Kazan (Volga Region) Federal University, Kazan, Russian Federation.

E-mail: garifullin@mail.ru

Abstract submitted to: Winter Conferences of Sports Science. Costa Blanca Sports Science Events, 22-23 March 2021. Alicante, Spain.

JOURNAL OF HUMAN SPORT \& EXERCISE ISSN 1988-5202.

(c) Faculty of Education. University of Alicante.

doi:10.14198/jhse.2021.16.Proc3.37
\end{abstract}




\section{INTRODUCTION}

One of the urgent problems of migrant students is the problem of their psychological adaptation and acculturation in the country in which they study. The adaptation processes of migrant students have various components. One of these components is the attitude towards migrant students by local residents and students. World statistics confirm the existence of bullying and cyberbullying in relation to migrant students. In addition, there are statistics of crimes related to bullying against migrant students. In this article, we tried to identify and study students and young people who are prone to bullying and cyberbullying.

Despite the fact that personality traits associated with emotional insensitivity or coldness play an essential role in the phenomenon of cyberbullying, the intermediary mechanisms and components of the cyberbullying phenomenon have been little studied. This article will examine the mediation function of justifying immoral behaviour, which interconnects traits associated with emotional insensitivity and the act of cyberbullying, as activities that limit the processes of empathy.

\section{Review of literature}

The problem of cyberbullying is a serious problem for youth as the number of Internet users is growing every year (Yilmaz, 2010; Mejia et al, 2019; Mikhaylovsky et al, 2019; Tabachuk et al., 2018). A significant part of young people use smartphones (de Arriba Pérez et al., 2016; Park \& Kim, 2018; Marques \& Pitarma, 2016; Jeong, 2017). A large proportion of students are engaged in cyberbullying. Our preliminary analysis showed that cyberbullying increases dramatically in high school. Then these students continue their traditions in higher education institutions or colleges. Cyberbullying is an aggression that periodically and deliberately manifests itself on the Internet against those who are not capable of protecting against this aggression (Kowalski et al., 2014). Cyberbullying leads to various mental suffering of the victim: anxiety, depression and even suicide. (Kowalski et al., 2014).

Therefore, the study of all of the above factors contributing to the increase or decrease of youth cyberbullying is relevant. Emotional insensitivity of youth, as an essential component, can predict the occurrence of cyberbullying among adolescents and youths (Fanti, Demetriou \& Hawa, 2012; Orue \& Andershed, 2015). However, there is little research on how emotional insensitivity affects student cyberbullying.

Thus, the goal of this paper was to find a way to predict cyberbullying based on an assessment of the emotional insensitivity of university and college students. In addition, the goal was to study the intermediate mechanisms of regulating the relationship of emotional insensitivity and cyberbullying.

Traits associated with emotional insensitivity (hereinafter referred to as El) are characterized by the fact that the person in this case lacks remorse and guilt, and also has a low level of anxiety caused by his negative and destructive behaviour towards other people (Frick et al., 2014).

El traits usually lead to serious acts of aggression and abuse (Frick et al., 2014). Correlation analysis showed that El scores were significant and positively associated with destructive behaviour. In addition, there are works in which it is shown that due to the influence of the Internet, cyberbullying increases significantly (Orue \& Andershed, 2015).

The results of studies show that the signs of El can well predict cyberbullying of adolescents during (Fanti, Demetriou \& Hawa, 2012). 
It is important to note that the traits associated with the emotional insensitivity (EI) of Chinese teens are higher than the traits of the El of American teens. All this is the result of Chinese cultural tradition associated with the suppression of the desire for emotional relaxation. Lack of emotional discharge leads to emotional isolation and loneliness. As a result, the Chinese are not able to recognize the emotions of other people: sadness, suffering, and others (Leung et al., 2018; Crocetti et al., 2016; Batanova \& Loukas, 2011; Thornberg \& Jungert, 2017). In this situation, with the emotional state of the Chinese, there is a desire to engage in cyberbullying. Therefore, based on the foregoing, it can be assumed that the features of El will be a means for predicting student cyberbullying.

Justification of immoral behaviour as an intermediate mechanism. Justification of immoral behaviour (hereinafter referred to as IB) is a psychological defence and self-regulation, with the help of which people justify their immoral actions in order to look less immoral. Thanks to this, their suffering and empathy are reduced, caused by the suffering that they cause in their own. Using a model of general aggression (GAM), we proposed that justifying immoral behaviour could be an intermediate psychological mechanism between the El traits and cyberbullying. The GAM model highlights several levels that explain aggressive behaviour. These are personal and situational reasons, internal mental states and assessment of decision making. Personal reasons are associated with situational reasons, affecting the internal conditions leading to aggression and cyberbullying. According to the GAM, traits that justify immoral behaviour influence the personality's propensity for aggression and cyberbullying, transforming social cognitive processes. In essence, this is a mechanism to justify aggressive behaviour.

There is research that suggests that justifying immoral behaviour mediates the relationship between traits of emotional insensitivity and aggression. This assumption is fully justified, since the justification of immoral behaviour acts as an intermediate element between the traits of emotional insensitivity and cyberbullying. Later we will review the results of previous studies that support this assumption.

It should be noted that individuals with a significant El score are more likely to exhibit a high level of protection of immoral behaviour (IB).

According to the model of the development of a criminal lifestyle, emotional insensitivity can lead to an increase in criminal thinking, and subsequently to immoral behaviour. All this leads to offenses and crimes. In addition, studies by some authors show that emotional insensitivity (EI) in adolescents can cause justification of immoral behaviour, behavioural abnormalities, immoral behaviour and immoral behaviour of students. Many studies indicate that the first signs of emotional insensitivity become the cause of immorality, justification of immorality in adolescents in a year.

In addition, it should be noted that college students with a high level of immorality and justification of their immoral acts are more often involved in bullying others and cyberbullying (Zhou, Zheng \& Gao, 2019). In addition, the ability to justify immoral behaviour (IB) can lead to cyberbullying in a year, despite control and limitations (Bussey, Quinn \& Dobson, 2015). The results of correlation analysis also indicate that individuals with a high level of immoral justification are more often involved (Chen, Ho \& Lwin, 2017). The influence of the justification of immoral personality behaviour on antisocial behaviour is strong and does not change, compared with the influence of emotional insensitivity El. This suggests that the role of emotional insensitivity of $\mathrm{El}$ in the processes of antisocial personality behaviour is different from the role of justification of immoral behaviour of IB. 
Empathy as a regulator. Although emotional insensitivity of El can lead to cyberbullying, due to the intermediate mechanism associated with justifying immoral behaviour of IB, not all people with large El clearly have a high level of immorality leading to cyberbullying. Therefore, it is necessary to investigate additional regulatory mechanisms that may affect the interaction of emotional insensitivity and cyberbullying. In this article, we plan to test the hypothesis that the connection between emotional insensitivity and cyberbullying is weakening, thanks to the phenomenon of empathy. Empathy in this article was understood as the ability to know the emotions of others (cognitive empathy) and share one's emotional state (affective empathy). The results obtained on the basis of the correlation analysis indicate that people with high empathy are less engaged (Kowalski et al., 2014). According to the analysis of risk and protection factors, cyberbullying is a product of the interaction of risk and protection factors.

350 students aged $19-20$ years were studied. Of these, $43 \%$ are girls. Emotional insensitivity (EI) was studied using the method of "Determining the signs of emotional insensitivity" (Frick et al., 2014). It was a selfreporting questionnaire consisting of 24 items. This questionnaire included three parts: heartlessness, indifference and lack of emotions. . A representative point was the expression: "The feelings of other people are not important to me." Each element of the survey was rated from 1 to 4 . In this study, the Cronbach coefficient a was 0.91 . Responses to 24 items were averaged. Higher scores indicated higher levels of signs of emotional insensitivity El.

The level of justification for immoral behaviour was evaluated on a scale of civil morality and consisted of 32 points with a rating of 1 to 5 points. 5 points - I completely agree with the statement. Responses to 32 points were averaged, with higher scores indicating a higher level of justification for immoral IB behaviour. A representative point was the expression: "Opponents deserve humiliation and abuse." In this study, the Cronbach coefficient a was 0.98 .

The level of cyberbullying of the subjects was determined on a scale of electronic bullying.

Subjects recorded in polls the number of cyberbullying events in the past. It was seven days on a 7-point scale. This electronic bullying scale has been developed for adolescents in the Chinese population. Its psychometric properties have been studied in the Chinese teenage population. This scale showed good reliability and reliability in the study of Chinese students. Answers on six points were averaged. Higher scores indicate a higher level of cyberbullying. In this study, the Cronbach coefficient a was 0.92. Empathy was measured using a baseline scale. Questionnaires consisted of 20 points. They included two aspects. The first aspect is cognitive empathy. The second is affective empathy. The key expression at these points was: "When someone is feeling unwell, I usually can understand how he is feeling." Each item was rated from 1 (disagree) to 5 (agree). Responses to 20 points were averaged. Students agreed to all of these studies. The study was anonymous.

It took about 40 minutes to fill out all the questionnaires. We checked all the questionnaires for completeness when the participants finished filling out the questionnaires.

\section{MATERIALS AND METHODS}

The fundamental basis of this study was the assessment of emotional insensitivity using the method of "Determining the signs of emotional insensitivity". 350 students at Kazan Federal University aged 19-20 years were studied. $43 \%$ of them are girls. A self-reporting questionnaire consisting of 24 items was used. This questionnaire consisted of three parts: callousness, indifference, and lack of emotion. The representative 
point was the expression: "other people's feelings are not important to me. "Each element of the survey was rated from 1 to 4 points. The answers to 24 questions were averaged. Higher scores indicated a higher level of signs of emotional insensitivity.

\section{RESULTS AND DISCUSSION}

Correlation analysis showed that the level of emotional insensitivity had a positive correlation with the level of justification for immoral behaviour. The level of cyberbullying of the subjects had a negative correlation with the level of empathy. The level of justification for immoral behaviour had a positive correlation with cyberbullying and a negative correlation with the level of empathy. Cyberbullying negatively correlated with empathy.

The level of emotional insensitivity (EI) was positively correlated with the level of justification for immoral behaviour IB, which in turn was positively associated with cyberbullying. A positive direct correlation between the level of El and the level of cyberbullying was significant. Thus, it can be said that the level of justification of immoral behaviour of IB to some extent supported an intermediate mechanism between the level of emotional insensitivity of El and the level of cyberbullying. The mediation effect accounted for $55.20 \%$ of the total effect of the El emotional insensitivity traits on cyberbullying.

For clarity, we compared the predicted levels of justification for immoral behaviour of IB with the level of emotional insensitivity. We made this comparison first for a low, and then for a high level of empathy. This comparison showed that for students with a low level of empathy, the traits of El emotional insensitivity strongly influence the emergence of excuses for immoral IB behaviour. Moreover, for students with a high level of empathy, the traits of emotional insensitivity El significantly affect the justification of immoral behaviour of IB, but much weaker. In addition, the results obtained and their analysis showed that the justification of the immorality of IB and empathy had a significant impact on the occurrence of cyberbullying.

Next, we compared the rates of perceived cyberbullying and the level of justification for immorality at low and high levels of empathy. This comparison showed that the level of justification for immorality of IB most often led to cyberbullying in the presence of high level empathy and low level empathy. At the same time, the expected level of justification for immorality of IB in the presence of cyberbullying was more significant for students with a low level of empathy than for students with a high level of empathy.

However, the deterrent effect of empathy was not significant in the relationship between the emotional insensitivity of El and cyberbullying. Correctional analysis showed that the indirect effect of the emotional insensitivity of EI on cyberbullying, thanks to the intermediate role of justifying the immorality of IB, was mitigated by empathy. For students with high empathy, the indirect relationship between El emotional insensitivity and cyberbullying was significant. For college students with low empathy, the indirect relationship between the traits of El emotional insensitivity and the occurrence of cyberbullying was also stronger. Thus, the analysis showed that empathy softened the indirect link between the emotional insensitivity of El and cyberbullying, thanks to the justification of the immorality of IB.

Despite the fact that there is already a lot of research on the significant impact of El emotional insensitivity on adolescent cyberbullying (Zhou, Zheng \& Gao, 2019), however, there is much less research on the effect of increased El emotional insensitivity on the occurrence of student cyberbullying. At the same time, it should be noted that no intermediate mechanisms between the level of emotional insensitivity of $\mathrm{El}$ and cyberbullying, which lead to containment of the act of cyberbullying, have yet to be identified. 
Thus, our results obtained using correlation analysis showed a negative effect of emotional insensitivity of El on cyberbullying. In addition, the indirect relationship between the emotional insensitivity of El and cyberbullying, due to the intermediate effect of justifying the immorality of $\mathrm{IB}$, was weak due to the high empathy of students.

Despite the fact that it was previously shown that the level of justification of immorality of IB is a key intermediate mechanism connecting the personality traits of students (anger, sympathy, etc.) and cyberbullying (Zhou, Zheng \& Gao, 2019), this our study for the first time demonstrated the intermediate effect of justification of immorality of IB in the relationships between El emotional insensitivity and excuses for immorality IB. Thus, the level of justification for immorality of IB can serve as a "bridge" linking the emotional insensitivity of El with students' cyberbullying. Our results are beyond the scope of previous studies and show why emotional insensitivity of El can enhance and contribute to students' cyberbullying. Our findings are consistent with the general model. In other words, risk factors (for example, emotional insensitivity of El) can contribute to the inclusion of mechanisms to justify the immorality of IB, which, in turn, increases the likelihood of cyberbullying.

Thus, justification of the immorality of IB is not only the result of the influence of emotional insensitivity of El, but also a catalyst for cyberbullying. At the same time, it should be noted that the justification of the immorality of IB only partially mediated the relationship between the emotional insensitivity of El and cyberbullying. The continuing direct and positive correlation between the emotional insensitivity of the El and cyberbullying may indicate that the emotional insensitivity of the El can influence without mediation, thereby increasing the level of student cyberbullying.

It should be noted that each of the individual components in our mediation model deserves attention to the general conclusions about the intermediate mechanisms between the various personality traits of students. At the initial stage, it has an intermediate mechanism $\mathrm{EI} \rightarrow \mathrm{IB}$. Our analysis and observations have shown that the emotional insensitivity of El greatly facilitates the processes of including mechanisms for justifying the immorality of IB. What is the reason for this? This is due to the fact that people with emotional insensitivity show a low level of fear and insensitivity to punishment. Therefore, this emotional insensitivity interferes with the assimilation of moral norms of behaviour and leads to ignoring the consequences of immoral behaviour. In addition, people with emotional insensitivity are insensitive to negative emotions and can hardly recognize them (Frick et al., 2014). This lack of ability to detect negative emotions can lead to the fact that they can easily ignore the anxiety that they cause the victim while continuing to move towards their goal. Finally, people with El emotional insensitivity are not averse to immoral behaviour, but they also have a sense of expectation and happiness, allowing them to turn on a protective mechanism to justify their immoral IB actions.

At the next stage of the development of the intermediate mechanism IB $\rightarrow$ cyberbullying, our studies showed that the justification of the immorality of IB was associated with a large amount of cyberbullying. According to the theory of justification of immoral behaviour of IB, the strengthening of the mechanism of justification of immorality of IB leads to a violation of the moral self-regulation function of the individual and to the restoration of cyberbullying. These excuse processes are designed to make cyberbullying seem less harmful to others or not harmful to others. In the end, it reduces the guilt as well as the students' guilt and increases the likelihood of an act of cyberbullying.

In the process of our analysis, we found two more reasons due to which the justification of the immorality of $\mathrm{IB}$ is strictly connected with the cyberbullying of students. This reason is the early experience of cognitive 
reconstruction of immoral behaviour, which is already embedded in the normal behaviour of the individual and leads to the rationalization of his immoral behaviour in the future. Thus, students can be more experienced and effective in enhancing and incorporating protective mechanisms to justify their immorality $\mathrm{IB}$ and begin to engage in cyberbullying.

The next reason is the lack of effective moral hints and restrictions on moral rules and ethics in online communications, as well as the low self-discipline of individuals that accelerate the emergence of the phenomenon of justification of immorality IB and, as a result, lead to the emergence of cyberbullying.

\section{CONCLUSION}

1. Our studies have shown that empathy mitigates the adverse effects of emotional insensitivity on the processes of justification of immorality and according to the correlation analysis, there is a negative effect of the justification of immorality on cyberbullying.

2. This study is an important step in revealing the emotional characteristics of students who are inclined to engage in cyberbullying. It is shown that the phenomenon of justification of cyberbullying is one of the potential mechanisms by which emotional features begin to affect the ability of students to engage in cyberbullying. Attention to the phenomenon of justification of cyberbullying reveals the relationship of emotional characteristics and cyberbullying.

3. At the same time, the justification of immoral behaviour was a mediating mechanism between emotional insensitivity and cyberbullying. In addition, an analysis of mediating mechanisms showed that empathy regulated the relationship between emotional insensitivity and the justification of immoral behaviour, as well as between the justification of immoral behaviour and cyberbullying. These two connections were less pronounced in students with a high level of empathy. Thanks to the results, a mechanism has been identified that can reduce the effect of emotional insensitivity on students' cyberbullying.

Students with a high level of empathy can well understand the emotions of others. Therefore, they are less likely to justify immorality by reconstructing or rationalizing their antisocial behaviour associated with cyberbullying. Moreover, students with a high level of empathy are more likely to recognize the harmful effects of activating the processes of justification of immorality and cyberbullying. Therefore, they are less likely to cyberbully.

\section{ACKNOWLEDGMENTS}

The work is performed according to the Russian Government Program of Competitive Growth of Kazan Federal University.

\section{REFERENCES}

Batanova, M. \& Loukas, A. (2011). Social anxiety and aggression in Early Adolescents: Examining the Moderating Roles of empathic concern and perspective taking. Journal of Youth and Adolescence, 40, 1534-1543. https://doi.org/10.1007/s10964-011-9634-x

Bussey, K., Quinn, C. \& Dobson, J. (2015). The moderating role of empathic concern and perspective taking on the relationship between moral disengagement and aggression. Merrill-Palmer Quarterly, 61(1), 10-29. https://doi.org/10.13110/merrpalmquar1982.61.1.0010 
Chen, L., Ho, S.S. \& Lwin, M.O. (2017). A meta-analysis of factors predicting cyberbullying perpetration and victimization: From the social cognitive and media effects approach. New Media and Society, 19, 1194-1213. https://doi.org/10.1177/1461444816634037

Crocetti, E., Van der Graaff, J., Moscatelli, S., Keijsers, L., Koot, H.M., Rubini, M., Meeus, W. \& Branje, S. (2016). A longitudinal study on the effects of parental monitoring on adolescent antisocial behaviors: The moderating role of adolescent empathy. Frontiers in psychology, 7, 1726. https://doi.org/10.3389/fpsyg. 2016.01726

De Arriba Pérez, F., Santos Gago, J. M. \& Caeiro Rodríguez, M. (2016). Analytics of biometric data from wearable devices to support teaching and learning activities. Journal of Information Systems Engineering and Management, 1(1), 41-54. https://doi.org/10.20897/lectito.201608

Fanti, K.A., Demetriou, A.G. \& Hawa, V.V. (2012). A longitudinal study of cyberbullying: Examining risk and protective factors. European Journal of Developmental Psychology, 9(2), 168-181. https://doi.org/10.1080/17405629.2011.643169

Frick, P.J., Ray, J.V., Thornton, L.C. \& Kahn, R.E. (2014). Can callous-unemotional traits enhance the understanding, diagnosis, and treatment of serious conduct problems in children and adolescents? A comprehensive review. Psychological Bulletin, 140(1), 1-57. https://doi.org/10.1037/a0033076

Jeong, H. (2017). Effects of Nursing Students' Practices using Smartphone Videos on Fundamental Nursing Skills, Self-efficacy, and Learning Satisfaction in South Korea. Eurasia Journal of Mathematics, Science and Technology Education, 13(6), 2351-2365. https://doi.org/10.12973/eurasia.2017.01229a

Kowalski, R.M., Giumetti, G.W., Schroeder, A.N. \& Lattanner, M.R. (2014). Bullying in the digital age: A critical review and meta-analysis of cyberbullying research among youth. Psychological Bulletin, 140, 1073-1137. https://doi.org/10.1037/a0035618

Leung, A.N.M., Wong, N. \& Farver, J.M. (2018). Cyberbullying in Hong Kong Chinese students: life satisfaction, and the moderating role of friendship qualities on cyberbullying victimization and perpetration. Personality and Individual Differences, 133, 7-12. https://doi.org/10.1016/i.paid.2017.07.016

Marques, G.M.S. \& Pitarma, R. (2016). Smartphone Application for Enhanced Indoor Health Environments. Journal of Information Systems Engineering and Management, 1(4), 49. https://doi.org/10.20897/lectito.201649

Mejia, C.R., Mena, L.S., Mogollón, C.A., Figueroa-Romero, R., Hernández-Calderón, E.N., AguilarFernández, A.M. \& Hernández-Arriaga, G. (2019). Compulsive gaming in secondary school students from five Peruvian cities: Usage and addiction to the Pokémon GO game. Electronic Journal of General Medicine, 16(5), em164. https://doi.org/10.29333/ejgm/114664

Mikhaylovsky, M.N., Lopatkova, I.V., Komarova, N.M., Rueva, E.O., Tereschuk, K.S. \& Emelyanenkova, A.V. (2019). Cyberbulling as a new form of a threat: a physiological, psychological and medicinal aspects. Electronic Journal of General Medicine, 16(6), em161. https://doi.org/10.29333/ejgm/114268

Orue, I. \& Andershed, H. (2015). The Youth Psychopathic Traits Inventory-Short Version in Spanish adolescents-Factor structure, reliability, and relation with aggression, bullying, and cyber bullying. Journal of Psychopathology and Behavioral Assessment, 37, 563-575. https://doi.org/10.1007/s10862-015-9489-7

Park, K.Y. \& Kim, M.S. (2018). Outcomes of a Drug Dosage Calculation Training Smartphone App on Learning Achievement, Metacognition, and Flow State According to Prior Knowledge. Eurasia Journal of Mathematics, Science and Technology Education, 14(7), 2867-2876. https://doi.org/10.29333/ejmste/90984 
Tabachuk, N.P., Ledovskikh, I.A., Shulika, N.A., Kazinets, V.A. \& Polichka, A.E. (2018). Internet Activity and Internet Addiction: Where is the Borderline in Developing One's Information Competency? Eurasia Journal of Mathematics, Science and Technology Education, 14(12), em1640. https://doi.org/10.29333/ejmste/97828

Thornberg, R. \& Jungert, T. (2017). Callous-unemotional traits, harm-effect moral reasoning, and bullying among Swedish children. Child and Youth Care Forum, 46(4), 559-575. https://doi.org/10.1007/s10566-017-9395-0

Yilmaz, H. (2010). An Examination of Preservice Teachers' Perceptions about Cyberbullying. Eurasia Journal of Mathematics, Science and Technology Education, 6(4), 263-270. https://doi.org/10.12973/eimste/75248

Zhou, Y., Zheng, W. \& Gao, X. (2019). The relationship between the big five and cyberbullying among college students: the mediating effect of moral disengagement. Current Psychology, 38, 1162-1173. https://doi.org/10.1007/s12144-018-0005-6 